\title{
Avaliação química e atividades antioxidante e antifúngica dos óleos essenciais dos frutos verdes e maduros de Zanthoxylum rhoifolium (Lam.)
}

\author{
Antifungal and antioxidant activities of essential oils from green and ripe \\ fruits from Zanthoxylum rhoifolium (Lam.)
}

\author{
Antonio Carlos Pereira de Menezes Filho ${ }^{1}$, Marcela Christofoli Christofoli ${ }^{2}$, Wendel Cruvinel \\ Sousa ${ }^{3}$, Carlos Frederico de Souza Castro ${ }^{4}$
}

${ }^{1}$ Biólogo, Mestre em Agroquímica. Instituto Federal de Educação, Ciência e Tecnologia de Goiás, IFG. Rio Verde-GO Brasil. E-mail: astronomoamadorgoias@gmail.com *Autor para correspondência

${ }^{2}$ Bióloga, Mestre em Ciências Agrárias, Doutoranda em Biotecnologia e Biodiversidade. Universidade Federal de Goiás. Rio Verde-GO Brasil. E-mail: christofolimarcela@gmail.com

${ }^{3}$ Biólogo, Mestre em Agroquímica. Instituto Federal de Educação, Ciência e Tecnologia de Goiás, IFG. Rio Verde-GO Brasil. E-mail: wendelcruvinel@gmail.com

${ }^{4}$ Químico, Doutor em Química. Docente do Instituto Federal de Educação, Ciência e Tecnologia de Goiás, IFG. Rio Verde-GO Brasil. E-mail: carlosfsscastro@gmail.com

\section{Palavras-chave \\ Zanthoxylum \\ Sclerotinia sclerotiorum \\ Colletotrichum gloeosporioides \\ Aspergillus flavus}

\begin{abstract}
Keywords
Zanthoxylum

Sclerotinia sclerotiorum

Colletotrichum gloeosporioides

Aspergillus flavus
\end{abstract}

\begin{abstract}
Zanthoxylum rhoifolium é uma espécie frutífera encontrada em áreas de Cerrado brasileiro, apresentando frutos aromáticos com inúmeras ações biológicas registradas. O trabalho teve por objetivo avaliar a química e as atividades antioxidante e antifúngica em isolados de Sclerotinia sclerotiorum, Colletotrichum gloeosporioides e Aspergillus flavus a partir do óleo essencial dos frutos verdes e maduros. Os frutos foram coletados em área de cerradão localizado no estado de Goiás, Brasil. O óleo essencial foi extraído por hidrodestilação. Os ensaios químicos foram realizados por análise proximal (organoléptica) (aparência, cor, aroma e tato), rendimento, solubilidade em solução hidroetanólica $70 \%$, índice de refração, rotação óptica e densidade relativa. Para o ensaio antioxidante, foi utilizado modelo (2,2-difenil-1-picrilhidrazil), e para antifúngico em diferentes concentrações de óleo essencial pelo método de difusão em ágar. Foram obtidos importantes resultados de rendimento 0,82 e 1,46, solubilidade positiva, densidade relativa de 0,933 e 0,935 g mL-1 $20^{\circ} \mathrm{C}$, índice de refração de 1,3998 e 1,4015 e rotação óptica $\alpha D+35,6$ e $+36,7$, e para atividade antioxidante redução entre 100 a $19 \%$ e de 100 a $20 \%$ para o óleo essencial dos frutos verdes e maduros, respectivamente. E para atividade antifúngica, inibições de 80 e 55\% para S. sclerotiorum, 46 e $91 \%$ para $C$. gloeosporioides e de 21 e 44\% para A. flavus, respectivamente para o óleo essencial dos frutos verdes e maduros. Os óleos essenciais dos frutos de $Z$. rhoifolium apresentaram características importantes como nova fonte de óleo essencial, como agente antioxidante e antifúngica.
\end{abstract}

Zanthoxylum rhoifolium is a fruit species found in areas from the Brazilian Cerrado, presenting aromatic fruits with numerous registered biological actions. The work to evaluate the chemistry and antioxidant and antifungal activities in isolates of Sclerotinia sclerotiorum, Colletotrichum gloeosporioides and Aspergillus flavus from the essential oils of green and ripe fruits. The fruits were collected in a "cerradão" area in the state of "Goiás", Brazil. The essential oil was extracted by hydrodistillation. The chemical tests were performed by proximal (organoleptic) analysis (appearance, color, aroma and touch), yield, solubility in $70 \%$ hidroethanolic solution, refractive index, optical rotation and relative density. To the test antioxidant, it was used model (2,2diphenyl-1-picrylhydrazyl) and antifungal test, in different concentrations of the essential oils by the agar diffusion method. Important results were obtained, yield in 0.82 and $1.46 \%$, positive solubility, relative density of 0.933 and $0.935 \mathrm{~g} \mathrm{~mL}-1$ in $20^{\circ} \mathrm{C}$, refractive index from 1.3998 and 1.4015 and rotation optical $\alpha D+35.6$ and +36.7 , and for antioxidant activity reduction between 100 to $19 \%$, and 100 to $20 \%$ from the essential oils of green and ripe fruits, respectively. And for antifungal activity, inhibitions of 80 and $55 \%$ for S. sclerotiorum, 46 and $91 \%$ for $C$. gloeosporioides and, 21 and $44 \%$ from A. flavus, respectively, of the essential oils from green and ripe fruits. The essential oils from the fruits of Z. rhoifolium showed important characteristics as a new source of essential oils, as na antioxidant and antifungal agents.

\section{INTRODUÇÃO}

O domínio Cerrado é uma das maiores florestas do mundo, e é o segundo maior em área territorial e de espécies da flora e fauna no Brasil (LIMA et al., 2015). O Cerrado apresenta inúmeras áreas com alto endemismo de espécies 
vegetais (ROCHA; DO VALE, 2017), onde são identificadas cerca de 12.000 espécies (BORDINO et al., 2018). Dentre esta grande variabilidade biológica vegetal, encontra-se a espécie Zanthoxylum rhoifolium nativa, e conhecida popularmente por (mamica-de-cadela, carne-de-anta ou tinguaciba).

Zanthoxylum rhoifolium está entre as espécies de maior distribuição geográfica, ocorrendo desde o México até o Uruguai. No Brasil ocorre em praticamente todos os estados brasileiros desde o Norte ao Sul. Esta espécie pertence à família (Rutaceae), onde é facilmente encontrada no domínio Cerrado brasileiro habitando as fitofisionomias Cerrado sensu stricto, Cerrado denso e parque de Cerrado. Z. rhoifolium apresenta árvores com 3 a $15 \mathrm{~m}$ de altura, tronco e ramos aculeados; as folhas são imparipinadas, com tricomas estrelados a glabrescentes, odoríferas; as inflorescências são do tipo terminal ou nas axilas de folhas superiores; as flores são esverdeadas; os frutos maduros apresentam coloração preta apresentando numerosas glândulas salientes no pericarpo com aroma acentuado; as sementes possuem hilo linear (REFLORA, 2019; COSTA et al., 2017).

A espécie $Z$. rhoifolium apresenta compostos de óleos essenciais (OEs) produzidos a partir do metabolismo secundário do vegetal, estes OEs apresentam atividades biológicas importantes como carrapaticida (COÊLHO et al., 2019), antinociceptiva (PEREIRA et al., 2010), bactericida (BOEHME et al., 2008), antifúngica e inseticida (PRIETO et al., 2011), repente contra insetos (CHRISTOFOLI et al., 2015), antitumoral e anti-inflamatório (SILVA et al., 2007; LIMA et al., 2007). O OE dos frutos de Z. rhoifolium foi identificado por CGEM onde apresentou os seguintes compostos majoritários sabineno $55,94 \%$ e germacreno D com $17,12 \%$ sendo os compostos majoritários (COSTA et al., 2017).

Os OEs possuem importante função, de sequestro de radicais livres que causam sérios danos aos animais e humanos como vários tipos de cânceres. Um agente antioxidante é um composto que protege o sistema biológico contra os efeitos nocivos ocasionados pelos processos reativos como, por exemplo, o oxigênio singleto, que podem causar oxidação excessiva (MEZZA et al., 2018; SILVA et al., 2018; KRINSKY, 1994).

Os radicais livres apresentam papéis importantes no organismo, como na produção de energia, na fagocitose, sinalização intercelular e síntese de substâncias biológicas. Entretanto, seu excesso pode ocasionar efeitos negativos principalmente em nível de DNA, na produção de proteínas, organelas como as mitocôndrias envolvidas na produção energética (ALVES et al., 2010). Inúmeros trabalhos avaliaram OEs extraídos de inúmeras espécies vegetais, onde apresentaram importantes resultados de atividade antioxidante. As indústrias de alimentos e farmacêuticas utilizam agentes antioxidantes em seus processos alimentícios e na formulação de cremes, géis e hidratantes com óleos essenciais (ANDRADE et al., 2012; SILVESTRI et al., 2010).

Outra importante função observada em inúmeros OEs é a capacidade de inibir o crescimento de fungos, apresentando sensibilidade às formas de reprodução como as hifas e escleródios formas vegetativas. Inúmeros fungos apresentam patogenicidade para plantas de pequenas e grandes culturas, ocasionando sérias perdas de produção agrícola e proporcionando altos gastos com o uso de fungicidas agrícolas. O mofo-branco (Sclerotinia sclerotiorum (Lib.)) de Bary manifesta com maior intensidade nos períodos chuvosos nas culturas de soja, milho, algodão e grãos-de-bico (HAMID et al., 2018; SEIFBARGHI et al.; 2017; GRAU; HARTMAN, 2015).

Os ascoporos, produzidos nos apotécios, decorrentes da germinação carpogênica dos escleródios, que é a principal forma de infecção em plantas. Os escleródios podem ficar viáveis no solo por até 11 anos (SILVA et al., 2018). A antracnose é o nome dado à doença causada por diversos fungos do gênero Colletotrichum. É uma fitopatologia bem conhecida entre os fruticultores de banana, morango, mamão, abacate, noni e pimenta-de-cheiro, que causa podridão dos frutos em desenvolvimento e durante o armazenamento, sendo o Colletotrichum gloeosporioides (Penz.) um dos importantes fungos fitopatogênicos desse gênero (RIERA et al., 2019; DA SILVA et al. 2019; DA SILVA et al., 2018; YENJIT et al., 2010). Já o fitopatógeno Aspergillus flavus, produz toxinas micotoxinas e aflotoxinas que podem levar animais e humanos ao óbito. Estas toxinas estão envolvidas no desenvolvimento de vários tipos de cânceres e no aumento de células CD4 em pacientes imunodeprimidos e portadores do vírus da imunodeficiência adquirida, em inglês HIV (SAMSON et al., 2014). O A. flavus se desenvolve facilmente em grãos armazenados em armazéns como soja, milho, amendoim, algodão e nozes (DESHMUKH et al., 2020; MARTINAZZO et al., 2019; AMAIKE; KELLER, 2011).

Os antifúngicos agrícolas são produzidos com base na formulação sintética que agride o solo, água e as formas de vidas, principalmente insetos e o ser humano. Vários estudos demonstram a ação antifúngica e fungistática promovida pelos OEs, com isso, a necessidade de se desenvolverem agentes fúngicos naturais que não agridam o ambiente (MARTINAZZO et al., 2019; SILVA et al., 2018; BAGHERABADI et al., 2018).

$\mathrm{O}$ trabalho objetivou avaliar a atividade antifúngica frente a isolados de Sclerotinia sclerotiorum, Colletotrichum gloeosporioides e Aspergillus flavus e determinar a atividade antioxidante dos óleos essenciais extraídos dos frutos verdes e maduros de Zanthoxylum rhoifolium. 


\section{METODOLOGIA}

Os frutos verdes e maduros de Z. rhoifolium foram coletados no período diurno entre as 6-8 h. em uma área de Cerrado fitofisionomia cerradão localizada no município de Acreúna - Goiás, Brasil, com as seguintes coordenadas geográficas: $17^{\circ} 22^{\prime} 58.7^{\prime \prime} \mathrm{S} 50^{\circ} 23^{\prime} 32.5^{\prime \prime} \mathrm{W}$. A espécie foi identificada pela Draㅡ em Biotecnologia Marcela Christofoli, e uma exsicata foi herborizada e depositada no Herbário do IF Goiano, Campus Rio Verde, com o seguinte registro: HRV 1075. Os frutos foram separados manualmente em bandejas, e em seguida, foram pesadas alíquotas de $100 \mathrm{~g}$ em balança analítica digital (Marte, Mod. W220).

Cada alíquota foi processada em processador doméstico (Philco, Mod. HP900) com $500 \mathrm{~mL}$ de água destila, a solução foi transferida para sistema tipo Clevenger (TEFIC, Mod. TF500 ) onde ficou em refluxo por $3 \mathrm{~h}$. Em seguida, o hidrolato foi coletado e transferido para um funil de separação de 500 $\mathrm{mL}$ (Laborglas), onde a solução foi lavada três vezes com 30 $\mathrm{mL}$ de diclorometano (Alphatec, P.A - ACS, pureza 99,7\%). A fase orgânica foi coletada e seca com sulfato de sódio anidro (Fmaia, P.A - ACS, pureza 98,9\%) e filtrada em papel de filtro qualitativo faixa azul (Unifil, C42) logo após. O sobrenadante foi armazenado em béquer de $150 \mathrm{~mL}$ (Laborglas) envolto com papel alumínio onde ficou em local seco, ao abrigo de luz e em temperatura ambiente de $25{ }^{\circ} \mathrm{C}$ até completa evaporação do solvente residual. O OE foi então pesado em balança analítica digital (Marte, Mod. W220) e o rendimento determinado em porcentagem conforme a equação 1.

\section{Rend\% = (Massa de óleo/Massa in natura $) * 100$}

A solubilidade, densidade relativa, índice de refração e rotação óptica foi realizado conforme descrito por Alarcón et al. (2019). Para solubilidade, foi preparada solução hidroetanólica 70\% (v/v). Em Ependorff de 1,5 mL (Gene), foi acrescida $100 \mu \mathrm{L}$ da solução hidroetanólica $70 \%$, e $2 \mu \mathrm{L}$ de $\mathrm{OE}$, a solução foi agitada em Vortex (Fanem, Mod. 251) por 5 minutos. A densidade relativa foi realizada em picnômetro (Prolab) de $1 \mathrm{~mL}$. Alíquota de $1 \mathrm{~mL}$ de OE foi transferida para picnômetro limpo e seco previamente pesado, em seguida, o picnômetro com amostra teve sua massa aferida, e a densidade relativa a $20{ }^{\circ} \mathrm{C}$ expressa em g mL-1, conforme equação 2 .

$\mathrm{g} \mathrm{mL}^{-1} 20^{\circ} \mathrm{C}=[($ Pic + amostra $)-($ Pic vazio $)](\mathrm{g}) /$ Volume $\mathrm{OE}(\mathrm{mL})$

O índice de refração foi realizado, utilizando duas gotas de $\mathrm{OE}$ em refratrômetro digital (Hanna Instruments, Mod. HI96800) com índice de refração (1,2220 a 1,5080), resolução de 0,0001 a $20{ }^{\circ} \mathrm{C}$. A rotação óptica foi realizada em polarímetro com câmara de $10 \mathrm{~mL}$ na temperatura de $20^{\circ} \mathrm{C}$, e linha $\alpha D$ com lâmpada de sódio em 589,3 nm (Novainstruments, Mod. WXG-4), com faixa de medida de $180^{\circ}$ a $+180^{\circ}$ na escala Vernier. Uma solução etanólica de $\mathrm{OE}$ $10 \%$ foi preparada a partir do etanol (LChemicals, P.A - ACS, pureza $98,8 \%)$.

A atividade antioxidante foi determinada conforme Mezza et al. (2018) adaptado. Utilizou-se o radical livre 2,2-difenil-1picrilhidrazil, (DPPH) (Sigma-Aldrich, P.A -ACS, pureza 99\%). O ensaio antioxidante foi realizado pelo método de microdiluição em microplacas de 96 poços (Global Plast), utilizando leitora de microplacas (Hexis Científica, Mod. Versamax). Para cada poço foram adicionados $100 \mu \mathrm{L} \mathrm{mL}-1$ de uma solução hexânica de DPPH na concentração $0,06 \mathrm{mMol}$, $100 \mu \mathrm{L} \mathrm{mL} \mathrm{m}^{-1}$ de OE diluído em hexano nas seguintes concentrações de 50; 40; 30; $20 ; 10 ; 5 ; 2,5$ e $1,25 \mu \mathrm{L} \mathrm{mL}^{-1}$. A microplaca foi mantida em local escuro e em local resfriado 4 ${ }^{\circ} \mathrm{C}$. As leituras foram realizadas no comprimento de ondas em $517 \mathrm{~nm}$, após 1,5 h. de reação. Uma curva padrão foi realizada com a solução de DPPH na concentração 0,06 mMol. Como controle negativo utilizou-se a solução mãe de DPPH 0,06 mMol, e como branco o hexano (Alphatec, P.A -ACS, pureza $99,8 \%)$. Os resultados foram expressos em percentagem de redução de DPPH (\%).

Os isolados fungos mantidos em meio batata, dextrose, ágar (Kasvi - BDA) foram obtidos pelos laboratórios de Produtos Naturais e de Química Tecnológica. As cepas avaliadas foram Sclerotinia sclerotiorum, Colletotrichum gloeosporioides e Aspergillus flavus coletados em campos de produção de soja, e na fruticultura de mamão e maracujá, em Rio Verde, Morrinhos e Itumbiara, Goiás, Brasil. A atividade antifúngica foi determinada através da diluição seriada dos OEs em dimetilsulfóxido (DMSO) (Vetec, P.A - ACS, pureza $98,8 \%$ ). As concentrações partiram de 100 (óleo puro); 50; 25; 12,$5 ; 6,25 ; 3 ; 13$ e $1,25 \mu \mathrm{LL}^{-1}$. Como controle negativo, utilizou-se a testemunha (ausência de óleo) e DMSO, e como controle positivo fungicida Frowncide ${ }^{\circledR} 500$ SC (ISK, Fluazinam), na concentração pré-determinada de $10 \mu \mathrm{L} \mathrm{mL}^{-1}$ conforme descrito por Menezes Filho et al. (2019).

As concentrações do óleo essencial foram adicionadas ao meio de cultura BDA após esterilização e resfriamento com auxílio de uma alça de Drigalski de vidro, bem como para os tratamentos com fungicida comercial e DMSO. Após solidificação do meio, em câmara de fluxo laminar, 1 disco de micélio para cada cepa de $S$. sclerotiorum, $C$. gloeosporioides e A. flavus com $9 \mathrm{~mm}$ de diâmetro, foi depositado no centro da placa de Petri (SPlabor) de $10 \mathrm{~cm}$ de diâmetro. Em seguida foram incubadas à temperatura entre $20,23,28{ }^{\circ} \mathrm{C}$ respectivamente, conforme descrito por Garcia et al. (2012) e Deus et al. (2011), com adaptações. 
A avaliação consistiu em medições diárias do diâmetro para cada colônia, com auxílio de um paquímetro digital (Digimess, Mod. 100-174BI) $150 \mathrm{~nm}$, resolução de 0,01 $\mathrm{mm} / .0005$ ", iniciadas após 24 horas do início da incubação e encerradas, quando as colônias fúngicas, do tratamento testemunha, atingiram completamente a área interna da respectivamente.

$\mathrm{Na}$ Tabela 1, estão apresentados os resultados químicos dos OEs dos frutos verdes e maduros de Z. rhoifolium.

$O$ rendimento de $\mathrm{OE}$ para frutos verdes e maduros apresentaram satisfatório rendimento de extração, com diferença estatística entre as duas extrações (Tabela 1). Os

Tabela 1. Ensaios químicos para os óleos essenciais dos frutos verdes e maduros de Z. rhoifolium.

\begin{tabular}{lcc} 
Ensaios & OEFV & OEFM \\
\cline { 2 - 3 } Rendimento $(\%)$ & $0,82 \pm 0,02^{\mathrm{b}}$ & $1,46 \pm 0,01^{\mathrm{a}}$ \\
Solubilidade sol. 70\% & Positiva & Positiva \\
Densidade relativa $\mathbf{~} \mathbf{~ m L}^{\mathbf{- 1}} \mathbf{2 0}^{\circ} \mathbf{C}$ & $0,933 \pm 0,13^{\mathrm{a}}$ & $0,935 \pm 0,11^{\mathrm{a}}$ \\
Índice de refração & $1,3998 \pm 0,07^{\mathrm{a}}$ & $1,4015 \pm 0,05^{\mathrm{a}}$ \\
Rotação óptica $\alpha_{\mathbf{D}}$ & $+35,4^{\mathrm{a}}$ & $+36,9^{\mathrm{a}}$ \\
\hline
\end{tabular}

OEFV = óleo essencial fruto verde. OEFM = óleo essencial fruto maduro. Médias seguidas de ( \pm ). Letras iguais na mesma linha não diferem significativamente pelo teste estatístico de Student $(\mathrm{p} \leq 0,05)$. Fonte: Autores.

Tabela 2. Atividade antioxidante pela redução do radical livre DPP (\%) pelos óleos essenciais dos frutos verdes e maduros de Z. rhoifolium.

\begin{tabular}{lcc}
\hline Concentração mg mL & \multicolumn{2}{c}{$\begin{array}{c}\text { Atividade Antioxidante (\%) } \\
\text { OEFV }\end{array}$} \\
\cline { 2 - 3 } Puro & $100,00 \pm 0,05^{\mathrm{aA}}$ & $100,00 \pm 0,09^{\mathrm{aA}}$ \\
$\mathbf{5 0}$ & $94,81 \pm 0,02^{\mathrm{bA}}$ & $76,24 \pm 0,08^{\mathrm{bB}}$ \\
$\mathbf{4 0}$ & $84,11 \pm 0,05^{\mathrm{cB}}$ & $75,90 \pm 0,09^{\mathrm{bC}}$ \\
$\mathbf{3 0}$ & $63,44 \pm 0,08^{\mathrm{dB}}$ & $55,89 \pm 0,12^{\mathrm{cD}}$ \\
$\mathbf{2 0}$ & $51,33 \pm 0,06^{\mathrm{eC}}$ & $20,15 \pm 0,06^{\mathrm{dE}}$ \\
$\mathbf{1 0}$ & $44,01 \pm 0,13^{\mathrm{fD}}$ & - \\
$\mathbf{5}$ & $19,74 \pm 0,11^{\mathrm{gE}}$ & - \\
\hline
\end{tabular}

OEFV = óleo essencial fruto verde. OEFM = óleo essencial fruto maduro. Resultados referem à média de três repetições seguidos por $( \pm)$ desvio padrão. Os resultados na coluna seguida de letras diferentes apresentam diferença significativa $(\mathrm{p} \leq 0,05)$ pelo teste de Tukey. Fonte: Autores.

placa. A determinação do percentual de inibição de crescimento (PIC\%) foi realizada conforme proposto por Garcia et al. (2012). A equação utilizada foi \%PIC = (DTT DTQ)/DTT $\times 100$. PIC\% = percentual de inibição de crescimento, DTT = diâmetro no tratamento testemunha, DTQ = diâmetro no tratamento químico.

A análise estatística consistiu através de triplicatas para determinação para todos os ensaios, exceto para o ensaio antifúngico que foi realizado em quadruplicata, seguido de ( \pm ) desvio padrão das médias. Para as análises por diferença significativa, foram adotados os testes de Tukey e Student $\mathrm{p}<$ 0,05). O Software estatístico utilizado foi o PAST 3 (versão livre 2019).

\section{RESULTADOS E DISCUSSÃO}

Os OEs apresentaram visual transparente, límpido, coloração incolor e levemente amarelada, com aroma adocicado, oleoso ao tato para o fruto verde e maduro, frutos maduros apresentaram maior rendimento em comparação com os frutos verdes. Silva et al. (2007) encontraram rendimento de óleo essencial $0,84 \%$ para as folhas de Z. rhoifolium. Gonzaga et al. (2003) encontraram rendimento de óleos essenciais de 0,57; 1,5 e 0,45\% para folhas, frutos e flores de $Z$. rhoifolium respectivamente, e para o óleo dos frutos foram encontrados os seguintes compostos majoritários $\beta$-mirceno, (-)-linalool, menth-e-en-1-ol e (-)- $\alpha$ terpineol.

Estudo realizado por Prieto et al. (2011) avaliando o óleo dos frutos de $Z$. rhoifolium corrobora com o estudo realizado por Gonzaga et al. (2003) quanto aos compostos majoritários. Os pesquisadores ainda avaliaram os frutos de outras espécies do gênero Zanthoxylum, Z. monophyllum onde obtiveram os compostos majoritários sabineno, 1,8-cineole, hidrato de trans-sabineno, hidrato de cis-sabineno, e para $Z$. fagara germacreno $\mathrm{D}$, biciclogermacreno, epi- $\alpha$-muurolol e 5 neo-cedranol. O rendimento de óleo essencial de frutos maduros neste estudo está próximo ao observado pelos 
pesquisadores citados anteriormente.

Na Tabela 2 estão apresentados os resultados da atividade antioxidante pela redução do radicar livre DPPH pelos OEs dos frutos verdes e maduros de $Z$. rhoifolium em diferentes concentrações $\left(\mathrm{mg} \mathrm{mL}^{-1}\right)$. inibição micelial para o OE do fruto verde de Z. rhoifolium frente aos isolados de Sclerotinia sclerotiorum, Colletotrichum gloeosporioides e Aspergilus flavus.

Na Figura 2 observam-se as percentagens de inibição micelial para o OE dos frutos maduros de Z. rhoifolium frente

Figura 1. Porcentagem de inibição micelial PIC para o óleo essencial dos frutos verdes de Z. rhoifolium frente aos isolados de S. sclerotiorum, C. gloeosporioides e A. flavus. Letras iguais para concentrações do mesmo fungo não apresentam diferença estatística pelo teste de Tukey.

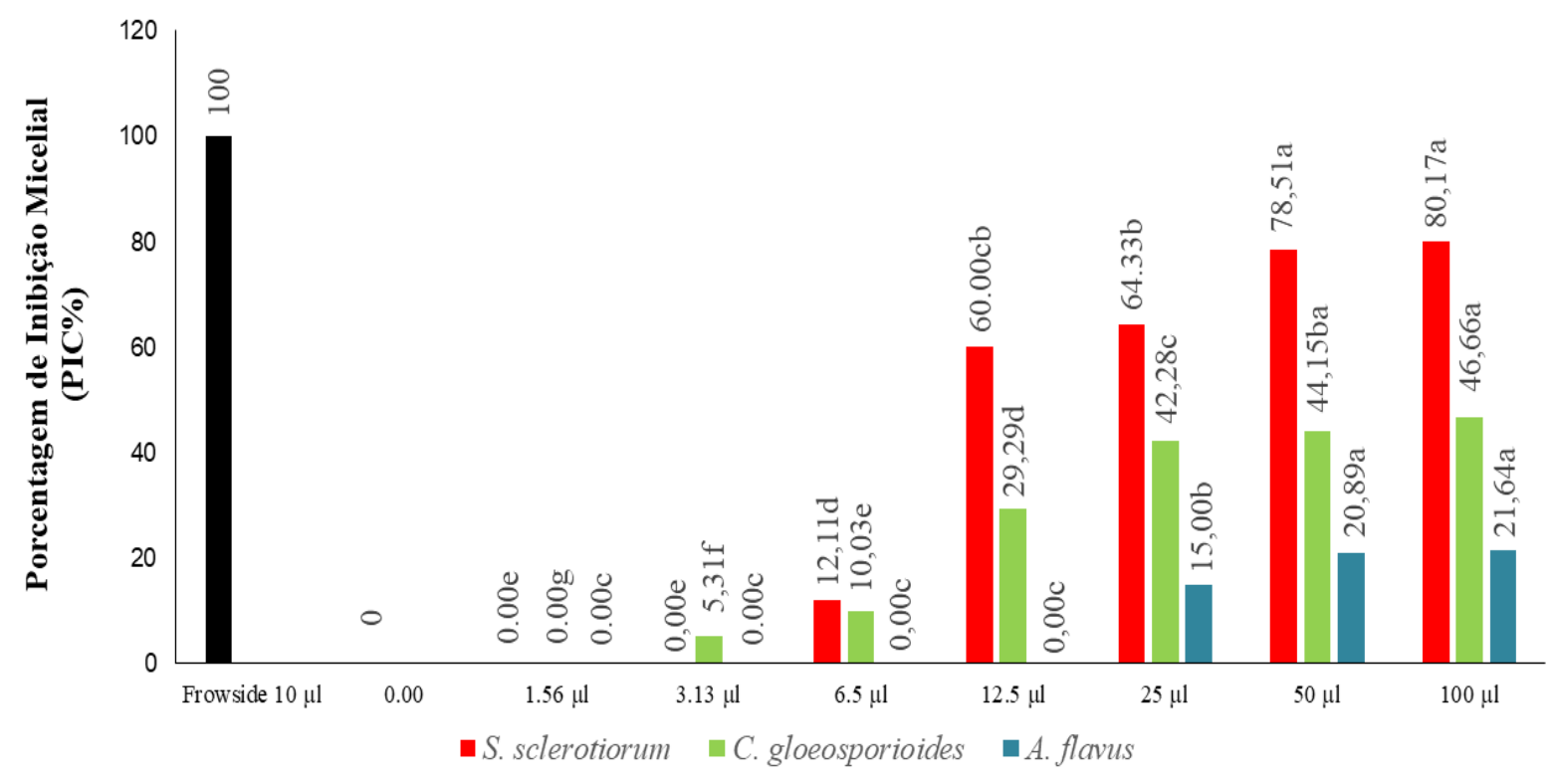

\section{Fonte: Autores}

Na Tabela 2, observa-se maior atividade antioxidante pelo OE dos frutos verdes com $100 \%$ de redução do radical livre DPPH no OE puro e na menor concentração usual com percentagem aproximada de $20 \%$. O OEs dos frutos maduros também proporcionou redução de $100 \%$ do radical DPPH no OE puro e na menor concentração com $20 \%$ apresentando serem OEs com alta capacidade de redução do radical modelo livre.

Menezes Filho e Castro (2019), encontraram também atividade antioxidante de $100 \%$ para concentrações de 50 e $40 \mu \mathrm{L} \mathrm{mL}^{-1}$ para o OE da raiz, e de $100 \%$ nas concentrações de 50 a $30 \mu \mathrm{L} \mathrm{mL}^{-1}$ para o OE das folhas de $C$. regium espécie vegetal também encontrada em ambientes de Cerrado. Os autores observaram maior atividade antioxidante para $\mathrm{O} O \mathrm{OE}$ das folhas mesmo em baixa concentração de $0,625 \mu \mathrm{L} \mathrm{mL}$ com atividade de $13,06 \%$ na redução do radical DPPH. ViudaMartos et al. (2010) avaliaram os OEs de tomilho, orégano, alho, salvia e alecrim onde obtiveram média entre 51,17 a $98,74 \%$, e EC50 de 0,090; 0,021; 0,023 e 35,56 respectivamente. Juteau et al. (2002), encontraram em estudo, apenas $18 \%$ de atividade antioxidante no OE de $A$. annua tendo como modelo o composto $\alpha$-tocoferol.

$\mathrm{Na}$ Figura 1 estão apresentadas as porcentagens de aos isolados de $S$. sclerotiorum, C. gloeosporioides e A. flavus.

Na Figura 1, observam-se a formação de três grupos com diferença estatística pelo teste de Tukey para o OE dos frutos verdes sobre o isolado de $S$. sclerotiorum, nas concentrações entre 100 e $50 \mu \mathrm{L} \mathrm{mL} \mathrm{m}^{-1}$ não há diferença estatística apresentando inibições de 80 e $78 \%$. Na concentração de 25 $\mu \mathrm{L} \mathrm{mL} \mathrm{L}^{-1}$ apresentou diferença entre o grupo $(a)$ e o grupo $(d)$, com $64 \%$ de inibição micelial. Na dose de $12,5 \mu \mathrm{L} \mathrm{mL}^{-1}$ não há diferença entre os grupos (b) e (c) com $60 \%$ de inibição. E o grupo $(d)$ na dose de $6,5 \mu \mathrm{L} \mathrm{mL}^{-1}$ com taxa de inibição de $12 \%$. Não foram observadas inibições nas menores concentrações de 3,13 e 1,56 $\mu \mathrm{L} \mathrm{mL}^{-1}$ apresentando o grupo $(f)$ conforme modelo estatístico adotado. Quando comparado ao OE dos frutos maduros, a taxa de inibição foi inferior como demonstrado na (Figura 2), com a formação de quatro grupos com diferença estatística. Entretanto, os resultados nas maiores concentrações de 100, 50, 25 e 12,5 $\mu \mathrm{L} \mathrm{mL}^{-1}$ foram de $55 ; 51 ; 38$ e $19 \%$, entretanto a concentração de $50 \mu \mathrm{LL}^{-1}$ não apresentou diferença significativa entre as demais concentrações usuais de OE. Nas menores concentrações de 6,5; 3,13 e 1,56 $\mu \mathrm{L} \mathrm{mL}^{-1}$ não foram observados PIC.

Para o isolado de C. gloeosporioides foi observado uma inversão das taxas de inibição como observado para o isolado 
de S. sclerotiorum, corroborando com Xavier et al. (2016), inferior a 50\%.

Figura 2. Porcentagem de inibição micelial para o óleo essencial dos frutos maduros de Z. rhoifolium frente aos isolados de $S$. sclerotiorum, $C$. gloeosporioides e A. flavus. Letras iguais para concentrações do mesmo fungo não apresentam diferença estatística pelo teste de Tukey.

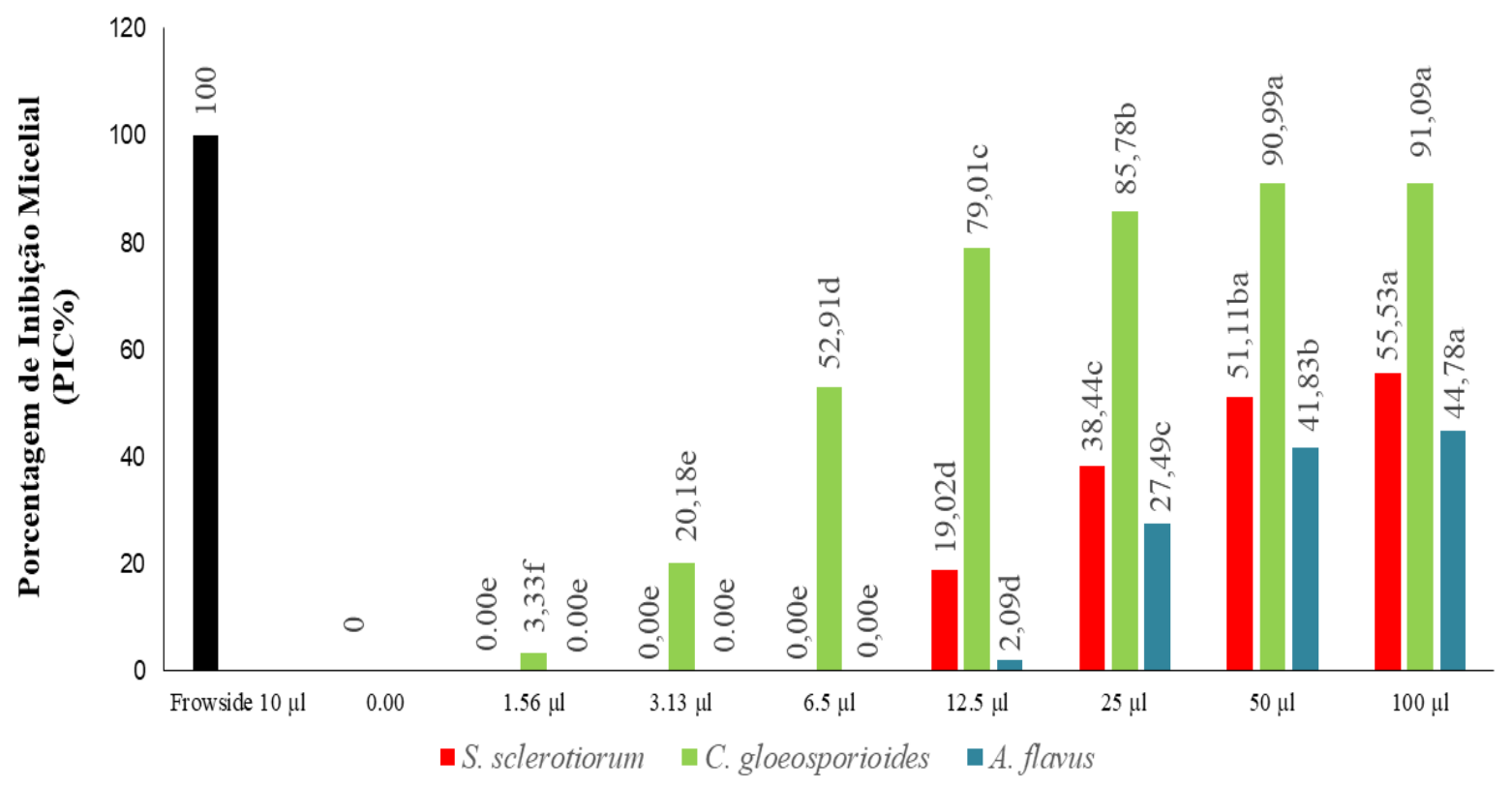

\section{Fonte: Autores}

Silva et al. (2018) e Souza et al. (2005) sobre os inúmeros mecanismos em que os óleos essenciais agem sobre os diferentes microorganismos. Na Figura 1, O OE dos frutos verdes apresentou menores taxas de inibição para $C$. gloeosporioides mesmo nas maiores concentrações de 100, 50, 25 e $12,5 \mu \mathrm{L} \mathrm{mL}^{-1}$, entretanto, não foram observados diferenças estatísticas entre as doses 100 e $50 \mu \mathrm{L} \mathrm{mL}^{-1}$ com resultados de $46 ; 44 ; 42$ e $29 \%$ respectivamente. Neste experimento houve a formação de seis grupos com diferença estatística. Na menor concentração de $1,56 \mu \mathrm{L} \mathrm{mL}^{-1}$ não foi observado PIC. Entretanto, o inverso foi observado para o OE dos frutos maduros como observado na (Figura 2). Nas concentrações 100 e $50 \mu \mathrm{L} \mathrm{mL} \mathrm{m}^{-1}$ não houve diferença significativa com inibição de 91 e 90\%. Já nas demais concentrações foram observadas inibição baixa e discreta até na menor concentração de $1,56 \mu \mathrm{L} \mathrm{mL}^{-1}$ com $3 \%$ de PIC.

Para o gênero Aspergillus, a espécie $A$. flavus foi a que apresentou menor sensibilidade em ambos os OEs dos frutos de Z. rhoifolium, demonstrando ser um isolado resistente possivelmente ao sinergismo dos OEs desta espécie vegetal frutífera. Na Figura 1, as concentrações 100 e $50 \mu \mathrm{L} \mathrm{mL}^{-1}$ não apresentaram diferença estatística com taxas de inibição de 21 e $20 \%$, respectivamente. Observou-se ainda, atividade de inibição miceliar até na concentração de $25 \mu \mathrm{L} \mathrm{mL}^{-1}$, as demais concentrações não apresentaram PIC para A. flavus. Na Figura 2, um leve aumento na taxa de inibição foi observado para o OE dos frutos maduros, entretanto, apresentando inibição
Neste estudo, foi observado cinco grupos com diferença estatística entre as concentrações, onde apenas foi observado ação de inibição nas maiores concentrações de 100, 50 e 25 $\mu \mathrm{L} \mathrm{mL} \mathrm{m}^{-1}$ com resultados de $44 ; 41$ e $27 \%$, respectivamente. Uma leve e discreta taxa de inibição foi observada na concentração de $12,5 \mu \mathrm{L} \mathrm{mL} \mathrm{m}^{-1}$ com $2 \%$, as demais concentrações não apresentaram PIC. Entretanto vale ressaltar que, a temperatura de incubação do $A$. flavus é de $28{ }^{\circ} \mathrm{C}$ neste estudo, possivelmente a baixa atividade de inibição pode estar relacionada a esse fator extrínseco ao quais os OEs foram submetidos.

A sensibilidade de $S$. sclerotiorum para os compostos do $\mathrm{OE}$ dos frutos verdes apresentou ser maior ocasionando elevada atividade antifúngica quando comparado aos frutos maduros. O contrário foi observado para o isolado de $C$. gloeosporioides que apresentou ser mais sensível ao OE dos frutos maduros. Já para $A$. flavus onde apresentaram as menores taxas de inibição entre os isolados testados. Com isso, abre a possibilidade de novos estudos para avaliarem diferentes espécies do gênero Aspergillus, e formular hipóteses sobre o sinergismo, temperatura ou o estudo de compostos isolados sobre a bioquímica deste gênero fúngico.

Outros estudos demonstraram situações variáveis na aplicação de OEs em outros grupos vegetais, frente aos três isolados avaliados neste estudo. Nos estudos de Silva et al. (2018), os pesquisadores encontraram atividade de inibição para S. sclerotiorum utilizando OE das folhas de $P$. guajava 
coletadas em dois períodos onde obtiveram atividade fungicida entre 77,5 a 94,9\% de inibição micelial. Dos Passos Braga et al. (2019), avaliaram três subtipos de $C$. gloeosporioides (CMM1767; CMM 24 e CMM 320) e dois OEs de M. piperita e Mentha $x$ villosa Huds. Onde obtiveram para MMC 1767 com inibição entre 11,5 a 100\%; para o subtipo CMM 24 de 14,0 a 84,6\% e para CMM 320 de 7,0 a 82,4\% para o OE de M. piperita; e de 7,5 a 100\% para o subtipo CMM1767 entre 17,8 a $89,0 \%$, e para o subtipo CMM 24 entre 11,0 a 77,00\%, e para CMM 320 em Mentha x villosa Huds. nas concentrações variáveis de 0,15 a $2,5 \mu \mathrm{L} \mathrm{mL}^{-1}$.

Estudo realizado por Boukaew et al. (2017), os investigadores avaliaram quatro OEs em 10 isolados de $A$. flavus, onde obtiveram taxas de inibição entre 14,98 a 34,36\% para o OE de C. annuum var. acuminatum; entre 27,84 a $76,95 \%$ para o OE de $C$. bejolghota; entre 58,76 a $100 \%$ para o OE de S. aromaticum e de 71,56 a $100 \%$ para o OE de $V$. diospyroides. Carotenuto et al. (2015), também observaram importante atividade de inibição micelial em frações do extrato de Z. rhoifolium para A. alternata, C. gloeosporioides, S. sclerotiorum, C. acutatum, B. cinerea, A. ustus, C. rosea e $P$. expansum. Prieto et al. (2011) avaliaram a porcentagem de inibição micelial em isolados de $C$. acutatum e F. oxysporum f. sp. lycopersici com taxas entre 10 a 50\% para os OEs dos frutos de Z. rhoifolium, Z. monophyllum e Z. fagara. Da Silva et al. (2006), avaliaram a ação inibitória mínima (MIC) do OE de $Z$. rhoifolium onde obtiveram inibição de $2,5 \mathrm{mg} \mathrm{mL}^{-1}$ para $A$. flavus.

Vale ressaltar que o gênero Zanthoxylum apresenta inúmeras ações biológicas a partir dos OEs extraídos em diferentes órgãos vegetais deste gênero. Estudo realizado por (CHRISTOFOLI et al. 2015) observaram importante atividade inseticida para O OE de Z. rhoifolium contra B. tabaci. O mesmo foi observado por Prieto et al. (2011) para os OEs de Z. rhoifolium, Z. monophyllum e Z. fagara contra S. oryzae. Importante ação bactericida também é observada para este gênero vegetal, em bactérias gram-positivas e gramnegativas, como relatado por Gonzaga et al. (2003). Boehme et al. (2008), observaram importante atividade citotóxica em células de carcinoma hepático e adenocarcinoma de mama e de carcionama prostático, bem como eficiente atividade bactericida para $S$. cereus, $B$. cereus, $E$. coli e $P$. aeruginosa, e alta sensibilidade tóxica para o modelo de $A$. salina.

Costa et al. (2008) também obtiveram considerável ação bactericida com o OE dos frutos frescos de Z. rhoifolium contra S. aureus, S. choleraesuis e S. flexneri, bem como potencial eficiência larvicida para $A$. aegypti, bem como, excepcional atividade antiviral para modelos em vegetais (MARTESCU et al., 2017), como também para os vírus do mosaico do tabaco avaliados no estudo de Lu et al. (2013). Entretanto, as inúmeras atividades biológicas não são observadas em todos os OEs, como nos estudos de Juteau et al. (2002), onde os pesquisadores não encontraram atividade bactericida para E. coli, S. aureus para o OE de A. annua.

De acordo com Souza et al. (2005) e Silva et al. (2018), os OEs possuem diferentes mecanismos de ação devido ao sinergismo e seus teores dos compostos sobre as diversas classes de microorganismos, corroborando com o observado nos testes de inibição micelial neste estudo para os três gêneros de isolados fúngicos avaliados.

\section{CONSIDERAÇÕES FINAIS}

Os frutos de Zanthoxylum rhoifolium tanto verdes quanto maduros apresentaram resultados químicos importantes, podendo ser uma possível nova fonte de extração para uso nas indústrias agrícola, de alimentos e farmacêutica devido aos excelentes resultados antioxidantes. Já para a atividade antifúngica é notável a ação fungistática para os isolados de Sclerotinia sclerotiorum e Colletotrichum gloeosporioides, entretanto, o mesmo não é observado para $A$. flavus que demonstrou ser resistente em todas as concentrações usuais. Como já discutido anteriormente, torna-se necessário outros estudos avaliando em especial essa espécie de Aspergillus em outras temperaturas de crescimento, isolando os compostos ou mesmo formular micro ou nano cápsulas como o polímero natural de quitosana composta com óleo essencial, podendo ser testado em ensaio in vitro ou in vivo em casas de vegetação ou em campo de plantio.

\section{AGRADECIMENTOS}

Ao Instituto Federal de Educação, Ciência e Tecnologia Goiano, Campus Rio Verde, GO; a Universidade Federal de Goiás, Campus Samambaia; a Universidade Federal de Jataí, Campus Jatobá; a Universidade Estadual de Goiás, Campus Santa Helena; aos Laboratórios de Química Tecnológica, Produtos Naturais, Fisiologia Vegetal, Sistemática Vegetal, Herbário e de Bioensaios e Biomoléculas; aos órgãos de fomento em pesquisa CAPES, CNPq, FINEP e FAPEG, esta última pelas bolsas de mestrado em Agroquímica para o primeiro autor Antonio e de Doutorado para a segunda autora Marcela.

\section{REFERÊNCIAS}

ALARCÓN MET, CONDE CG, MÉNDEZ GL. Extraccíon, caracterización y actividad antioxidante del aceite esencial de Eucalyptus globulus Labill. Revista Cubana de Farmacia. v. 52, n. 1, p. e266, 2019.

ALVES, CQ. et al. Métodos para determinação de atividade 
antioxidante in vitro em substratos orgânicos. Revista Química Nova, v. 33, n. 10, p. 2202-2210, 2010.

AMAIKE, S.; KELLER, NP. Aspergillus flavus. Annual Reviews Phytopathology, v. 49, p. 107-133, 2011.

ANDRADE, MA. et al. óleos essenciais de Cymbopogon nardus, Cinnamomum zeylanicum e Zingiber officinale: composição, atividades antioxidante e antibacteriana. Revista Ciência Agronômica, v. 43, n. 2, p. 399-408, 2012.

BAGHERABADI, S., ZAFARI, D., ANVAR, G. Colletotrichum gloeosporioides s. str., the causal agent of a leaf spot disease of Schefflera arboricola in Iran. Mycologia Iranica, v. 5, n. 1, p. 29-34, 2018.

BOEHME, AK. et al. Bioactivity and chemical composition of the leaf essential oils of Zanthoxylum rhoifolium and Zanthoxylum setulosum from Monteverde. Natural Product Research, v. 22, p. 31-36, 2008.

BORDINO, LF.; NETO, MJ.; BLINI, RCB. Levantamento florístico de um fragmento de Cerrado em recuperação no distrito industrial de Três Lagoas - MS. Revista Saúde e Meio Ambiente-RESMA, v. 6, n. 1, p. 45-55, 2018.

BOUKAEW, S.; PRASETSAN, P.; SATTAYASAMITSATHIL, $S$. Evaluation of antifungal activity of essential oils against aflatoxigenic Aspergillus flavus and their allelopathic activity from fumigation to protect maize seeds during storage. Industrial Crops and Products, v. 97, p. 558-566, 2017.

CAROTENUTO, G. et al. Fungistatic activity of Zanthoxylum rhoifolium Lam. bark extracts against fungal plant pathogens and investigation on mechanism of action in Botrytis cinerea. Natural Product Research, v. 29, n. 23, p. 2251-2255, 2015.

CHRISTOFOLI, M. et al. Insecticidal effect of nanoencapsulated essential oils from Zanthoxylum rhoifolium (Rutaceae) in Bemisia tabaci population. Industrial Crops and Product, v. 70, p. 301-308, 2015.

COÊLHO, MDG. et al. Controle do ectoparasita de bovinos Rhipicephalus (Boophilus) microplus, através do uso de óleo essencial do Cravo da Índia (Syzygium aromaticum) e óleo de Neem (Azadirachta indica). Revista Agrária Acadêmica, v. 2, n. 4, p. 203-210, 2019.

COSTA, ECC. et al. Essential oil repelente action of plants of the genus Zanthoxylum against Bemisia tabaci biotype $B$ (Homoptera: Aleyrodidae). Scientia Horticulturae, v. 226, p. 327-332, 2017.

COSTA, JGM. et al. Chemical composition, antibacterial and larvicidal activities of Zanthoxylum rhoifolium Lam. fruits essential oil. Journal of Essential oil Bearing Plants, v. 11, n. 6, p. 571-576, 2008.

DA SILVA, BNS. et al. Occurrence of noni anthracnose caused by Colletotrichum siamense in Amazonas, Brazil. Revista Agrária Acadêmica, v. 2, n. 3, p. 7-9, 2019.
DA SILVA, AM. et al. Diversidade morfológica, genética e patogenicidade de Colletotrichum spp. associados à pimenta-de-cheiro (Capsicum chinense Jacq.). Revista Agrária Acadêmica, v. 1, n. 4, p. 39-51, 2018.

DA SILVA, SL.; FIGUEIREDO, PMS.; YANO, T. Antibacterial and antifungal activities of volatile oil from Zanthoxylum rhoifolium leaves. Pharmaceutical Biology, v. 44, n. 9, p. 657-659, 2006.

DEUS, RJA.; ALVES, CN.; ARRUDA, MSP. Avaliação do efeito antifúngico do óleo resina e do óleo essencial de copaíba (Copaifera multijuga Hayne). Revista Brasileira de Plantas Medicinais, v. 13, n. 1, p. 1-7, 2011.

DESHMUKH, $\mathrm{H}$. et al. Galactosaminogalactan secreted from Aspergillus fumigatus and Aspergillus flavus induces platelet activation. Microbes and Infection, 2020.

DOS PASSOS BRAGA, S. et al. Application of coatings formed by chitosan and Mentha essential oils to control anthracnose caused by Colletotrichum gloeosporioides and C. brevisporum in papaya (Carica papaya L.) fruit. International Journal of Biological Macromolecules, v. 139, p. 1-9, 2019.

GRAU, CR. et al. Compendium of soybean diseases and pests. 5a Ed., St. Paul, MN: American Phytopathological Society, 2015. p. 59-62.

GONZAGA, WA. et al. Composition and antibacterial activity of the essential oils from Zanthoxylum rhoifolium. Planta Medica, v. 68, p. 8, p. 773-775, 2003.

HAMID, MR. et al. A novel Deltaflexivirus that infects the plant fungal pathogens, Sclerotinia sclerotiorum, can be transmitted among host vegetative incompatible strains. Viruses, v. 10, n. 6, 2018.

JUTEAU, F. et al. Antibacterial and antioxidant activities of Artemisia annua essential oil. Fitoterapia, v.73, p. 532-535, 2002.

KRINSKY, NI. The biological properties of carotenoids. Pure and Applied Chemistry, v. 66, p. 1003-1010, 1994.

LIMA, LM. et al. Anti-inflamatory and analgesic activities of the ethanolic extracts from Zanthoxylum riedelianum (Rutaceae) leaves and stem bark. Journal Pharmacy and Pharmacology, v. 59, n. 8, p. 1151-1158.

LIMA, PC. et al. Avaliação da capacidade leishmanicida de espécies vegetais do Cerrado. Revista de Patologia Tropical, v. 44, n. 1, p. 45-55, 2015.

LU, M.; HAN, Z.; XU, Y.; YAO, L. In vitro and in vivo anti-tobacco mosaic virus activities of essential oils and individual compounds. Journal of Microbiology and Biotechnology, $v$. 23, n. 6, p. 771-778, 2013.

MARTINAZZO, AP., OLIVEIRA, FS., TEODORO, CES. Antifungal activity of Cymbopogon citratus essential oil against Aspergillus flavus. Ciência e Natura, v. 41, p. 01-08, 2019.

MARUTESCU, L. et al. Botanical pesticides with virucidal, 
bactericidal, and fungicidal activity. New Pesticides and Soil Sensors, p. 311-335, 2017.

MENEZES FILHO, ACP.; CASTRO, CFS. Atividades antioxidante e antifúngica dos óleos essenciais de Cochlospermum regium frente à Sclerotinia sclerotiorum e Colletotrichum gloeosporioides. Revista Colloquium Agrariae, v. 15, n. 6, 2019.

MEZZA, GN, et al. Antioxidant activity of rosemary essential oil fractions obtained by molecular distillation and their effect on oxidative stability of sunflower oil. Food Chemistry, v. 242, p. 9-15, 2018.

PEREIRA, SS. et al. Antinociceptive effect of Zanthoxylum rhoifolium Lam. (Rutaceae) in models os acute pain in rodents. Journal of Ethnopharmacology, v. 129, p. 227231, 2010.

PRIETO, J.A. et al. Chemical composition, Insecticidal, and antifungal activities of fruit essential oils three Colombian Zanthoxylum species. Chilean Journal Agriculture Research, v. 71, p. 73-82, 2011.

REFLORA. Rutaceae in Flora do Brasil 2020 em construção. Jardim Botânico do Rio de Janeiro. Disponível em http://reflora.jbrj.gov.br/reflora/floradobrasil/FB1162. Acesso em 19 nov. 2019.

RIERA, N. et al. First report of Banana anthracnose caused by Colletotrichum gloeosporioides in Ecuador. An International Journal of Applied Plant Pathology Plant Disease, v. 103, n. 4, p. 763-763, 2019.

ROCHA, AAM.; DO VALE, VS. Diversidade alfa e beta de comunidades vegetais de Cerrado remanescentes nas beiras de estradas das margens de rodovias. Revista GETEC, v. 6, n. 13, p. 1-12, 2017.

SAMSON, RA. et al. Phylogeny, identification and nomenclature of the genus Aspergillus. Studies in Mycology, v. 78, p. 141-173, 2014.

SEIFBARGHI, S. et al. Changes in the Sclerotinia sclerotiorum transcriptome during infection of Brassica napus. BMC Genomics, v. 18, n. 266, 2017.

SILVA, SL.; FIGUEIREDO, PM.; YANO, T. Cytotoxic evaluation of essential oils from Zanthoxylum rhoifolium Lam. leaves. Acta Amazônica, v 37, n. 2, p. 281-286, 2007.

SILVA, EAJ. et al. Composição química do óleo essencial de folhas de Psidium guajava e sua toxicidade contra Sclerotinia sclerotiorum. Semina: Ciências Agrárias, v. 39, n. 2, p 865-874, 2018.

SILVA, LA. et al. Atividade antioxidante do óleo essencial de Myrcia sylvatica (G. Mey.) DC. por diferentes métodos de análises antioxidantes (ABTS, DPPH, FRAP, $\beta$ caroteno/ácido linoleico). Revista Fitos, v, 12, n. 2, p. 117 126, 2018.

SILVESTRI, JDF. et al. Perfil da composição química e atividades antibactericida e antioxidante do óleo essencial do cravo- da-índia (Eugenia caryophyllata Thumb.). Revista Ceres, v. 57, n. 5, p. 589-594, 2010.

SOUZA, EL. et al. Antimicrobial effectiveness of spices: na approach for use in food conservation systems. Brazilian Archives of Biology and Technology, v. 48, n. 4, p. 549-558, 2005.

VIUDA-MARTOS, M. et al. Antioxidant activity of essential oils of five spice plants widely used in a Mediterranean diet. Flavour and Fragrance Journal, v. 25, p. 13-19, 2010.

XAVIER, MN. et al. Composição química do óleo essencial de Cardiopetalum calophyllum Schltdl. (Annonaceae) e suas atividades antioxidante, antibacteriana e antifúngica. Revista Virtual de Química, v. 8, n. 5, 2016.

YENIT, P.; ISSARAKRAISILA, M.; INTANA, W.; CHANTRAPROMMA, K. Fungicidal activity of compounds extracted from the pericarp of Areca catechu against Colletotrichum gloeosporioides in vitro and in mango fruit. Postharvest Biology and Technology, v. 55, p. 129132, 2010.

Submissão: $17 / 05 / 2020$

Aprovado para publicação: 30/05/2020 